\title{
Preliminary study of the retention behavior for different compounds using cryogenic chromatography at different initial temperatures
}

\author{
Yawei Wang ${ }^{\mathrm{a}}$, Jiemin Liu ${ }^{\mathrm{b}}$, Ning Li ${ }^{\mathrm{a}}$, , Guoqing Shi ${ }^{\mathrm{b}}$, Guibin Jiang ${ }^{\mathrm{a}, *}$, Weiping $\mathrm{Ma}^{\mathrm{c}}$ \\ ${ }^{a}$ State Key Laboratory of Environmental Chemistry and Ecotoxicology, Research Center for Eco-Environmental Sciences, CAS, P.O. Box 2871, \\ Beijing 100085, China \\ ${ }^{\mathrm{b}}$ Department of Chemistry, Beijing University of Science and Technology, Beijing 100083, China \\ ${ }^{\mathrm{c}}$ Department of Chemistry, Lanzhou University, Lanzhou 730000, China
}

Received 3 January 2005; received in revised form 17 February 2005; accepted 18 February 2005

Available online 23 May 2005

\begin{abstract}
The Kováts indices $(I)$ of 24 volatile organic compounds were measured at the different initial temperatures by a laboratory-made cryogenic chromatography. The results show that the correlations of the Kováts indices and the temperature are nonlinear at low initial temperature. Seven QSRR models were built using the heuristic method at different initial temperatures by calculating the quantitative chemical parameters of 24 organic compounds to study the relationship between the retention behavior and the molecular parameters. By studying the relationship between carbon and retention behavior, the capacity factor, and resolution of selected compounds, the contribution of gas-liquid interfacial adsorption process, which influences the retention behavior of solutes, is becoming more and more important with the decrease of the initial temperature.
\end{abstract}

(C) 2005 Elsevier B.V. All rights reserved.

Keywords: Cryogenic chromatography; Kováts indices; Multiple linear regression (MLR)

\section{Introduction}

Gas chromatography (GC) has been one of the most powerful tools in analytical field. Unsurpassed as a separation technique, it produces one single value for each analyte, which may be used for identification purposes: the retention time, easily transformed into the retention volume, if the flow rate and the pressure conditions of the column are known. Theoretically, the retention index is only correlated with the temperature, the stationary phase's and solutes' structure. In fact, retention is a very complex physicochemical process that consists of a great number of parallel and consecutive unitary steps. It involves the interaction of a multitude of intermolecular forces, known as dispersion (or London forces), orientation (dipole-dipole or Keesom forces), induction (dipole-induced dipole or Debye forces), and electron donor-acceptor complexation, including hydro-

\footnotetext{
* Corresponding author. Tel.: +86 106284 9334; fax: +86 1062849179 .

E-mail address: gbjiang@mail.rcees.ac.cn (G. Jiang).
}

gen-bonding forces, leading to the partition of the solute between the gas and liquid phases [1-4]. Other factors, such as adsorption at the gas-liquid and liquid-support interfaces, steric hindrance of substituent groups within the solute molecule, etc., can also affect retention [5,6]. Martin produced a quantitative equation expanding the retention process [7]:

$V^{*}=V_{\mathrm{L}} K_{\mathrm{L}}+A_{\mathrm{GL}} K_{\mathrm{GL}}+A_{\mathrm{LS}} K_{\mathrm{GLS}}$

where $V^{*}$ and $V_{\mathrm{L}}$ are the net retention volume and stationary liquid volume, $A_{\mathrm{GL}}$ and $A_{\mathrm{LS}}$ are the surface of gas-liquid and liquid-support interfaces, $K_{\mathrm{L}}, K_{\mathrm{GL}}$ and $K_{\mathrm{GLS}}$ are the adsorption equilibrium constant of gas-liquid distribution, gas-liquid interfacial adsorption and liquid-support interfacial adsorption.

Due to this renowned complexity the process of retention can easily be affected by a small change in any single parameter, which characterizes a given chromatographic system (such as temperature, mobile phase flow rate, molecular level characteristics of a given stationary phase 
surface, diameter of stationary phase particles, etc.). In order to at least partially overcome this evident shortcoming, efforts have been made for each chromatographic mode to remove the unsatisfactory reproducibility of chromatographic results inherent of the method as a whole. Kováts index $(I)[8]$ which has proved to be successful in this respect in GC, is defined as:

$I_{X}=100\left(N+\frac{\lg t_{R(X)}^{\prime}-\lg t_{R(N)}^{\prime}}{\lg t_{R(N+1)}^{\prime}-\lg t_{R(N)}^{\prime}}\right)$

where $t_{R(N)}^{\prime}<t_{R(X)}^{\prime}<t_{R(N+1)}^{\prime}, t_{R(X)}^{\prime}$ is the adjusted retention time of a component $X$, and $t_{R(N)}^{\prime}$ and $t_{R(N+1)}^{\prime}$ are the adjusted retention times of $n$-alkanes with $N$ and $N+1$ carbon atoms. $n$-Alkanes are the retention index markers in the Kováts indices $\left(I_{X}\right)$ system. Their $I$ values are arbitrarily assigned to equal the carbon number atoms $(n)$ in the molecule multiplied by 100 [9].

In these years, temperature dependence of the retention data, especially of Kováts indices, has been studied for a long time $[10,11]$, although inconclusively to a large extent. In many cases, linear approximation provides excellent results within the commonly applied temperature ranges and for the nonpolar stationary phases $[11,12]$. However, the measurement of Kováts indices for a broad enough temperature range is particularly difficult. At lower temperatures, interaction between stationary phase and separated compounds is changed and the unwanted peak broadening restricts the applicable temperature ranges.

Thus, the objectives of this paper are to study the structural retention indices (Kováts indices) relationship and then to find the factors that influenced retention process at relative low initial temperature using cryogenic chromatography.

\section{Material and methods}

\subsection{Apparatus}

A nonliquid cryogenic gas chromatography using thermoelectric modules made by our laboratory for the cryogenic separation of low boiling point compounds was adopted. Thermoelectric modules were made of an array of semiconductor couples connected electrically in series and thermally in parallel. Further details of the system were given on our earlier publications [13,14].

Compounds were carried out in a $30 \mathrm{~m} \times 0.25 \mathrm{~mm} \times 0.25$ $\mu \mathrm{m}$ HP-1 capillary column by using a temperature program with initial hold a $2 \mathrm{~min}$ to $80{ }^{\circ} \mathrm{C}$ for $4 \mathrm{~min}$ and a ramp of 10 ${ }^{\circ} \mathrm{C} / \mathrm{min}$, which was controlled by the thermoelectric cryogenic system. The column flow offered by high pure $\mathrm{N}_{2}$ was controlled at $1 \mathrm{~mL} / \mathrm{min}$. The injector temperature was kept at $220{ }^{\circ} \mathrm{C}$. The temperature of the electronic pressure-controlled flame ionization detector was maintained at $250{ }^{\circ} \mathrm{C}$. The velocity of combustion gas, hydrogen, and combustion-supporting gas, air, were controlled at 30

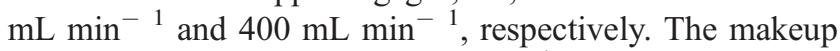
gas $\mathrm{N}_{2}$ is maintained at $20 \mathrm{~mL} \mathrm{~min}$ min $^{-1}$.

\subsection{Chemicals}

Organic compounds (Benzene toluene, ethylbenzene, $m$ and $p$-xylene, $o$-xylene, methyl acetate, ethyl acetate, butyl acetate, cyclohexane, isooctane, $n$-propanol, ethanol $n$-butanol, $n$-pentanol, $n$-hexanol, dichloromethane, 1,1-dichloroethane, trichloromethane, 1,2-dichloroethane, 1-chlorobutane, 1bromobutane, 1,1,2-triichloroethane, 1-bromopentane, 1-chlorohexane) obtained from Beijing Chemical Reagent Corporation were of $99.5 \%$ purity.

\subsection{CODESSA}

The software CODESSA, developed by Katritzky group $[15,16]$, can compute about 500 structural parameters including constitutional, topological, geometrical, electrostatic and quantum descriptors of the chemical compounds. It includes two multi-linear QSAR/QSPR equations (i) the heuristic method, and (ii) the best multi-linear regression method. The heuristic method for descriptor selection proceeds with a preselection of descriptors by eliminating sequentially descriptors which do not match any of the following criteria: (i) the $F$-test greater than one unit; (ii) $R^{2}$ value less than a value defined at the start (default 0.01); (iii) the Student's $t$-test less than that defined (default 0.1); and (iv) duplicate descriptors having a higher squared intercorrelation coefficient than a predetermined level (usually 0.8 ), retaining the descriptor with higher $R^{2}$ with reference to the property. The goodness of the correlation is tested by the correlation coefficient $\left(R^{2}\right)$, the $F$-test $(F)$, and the squared standard error $\left(s^{2}\right)$. The stability of the correlations was tested against the cross-validated coefficient, $R_{\mathrm{cv}}^{2}$. The $R_{\mathrm{cv}}^{2}$ describes the stability of a regression model obtained by focusing on the sensitivity of the model to the elimination of any single data point. The heuristic method's advantages are the high-speed and no restrictions on the size of the data set.

In this paper, molecules were modeled using the MM+ method of HyperChem Release 7.0 software (Hepercube, 2002). The precise optimization of compounds' structures was done with the semiempirical AM1 method in MOPAC6.0 [17]. The resulting geometry was transferred into software CODESSA. After the calculation of 380 molecular descriptors, including constitutional, topological, geometrical, electrostatic, and quantum-chemical descriptors, the heuristic method was used to select the structure descriptors that were correlated with the retention indices.

\section{Results and discussion}

Five benzene and its homologues, three esters, nine $n$ alkanes, five alcohols and nine halocarbons were chosen for 
our experiment. The retention indices of these compounds were measured in the $10{ }^{\circ} \mathrm{C}$ interval at the temperatures ranging from $0{ }^{\circ} \mathrm{C}$ to $60{ }^{\circ} \mathrm{C}$. The Kováts retention indices were calculated by Eq. (2). Table 1 summarizes the Kováts indices of 24 compounds at different temperature measured on HP-1 stationary phase.

\subsection{Structural-retention relationship}

After measured the Kováts indices, the software CODESSA, was used to study the quantitative structure retention relationship of these compounds at different initial temperature. By using the heuristic method, regression models were developed for the Kováts indices of 24 compounds at seven different initial temperatures. The heuristic correlations performed provide the optimal equations for different numbers of descriptors in the range of 17. Plots of $R^{2}$ and $R_{\mathrm{cv}}^{2}$ values against the number of descriptors (Fig. 1), which provide guidance regarding the number of descriptors to retain in the models, suggested that the best models in all regression contain four parameters. The descriptors involved in these correlations and seven of the best regression equations from each of the initial temperatures were listed in Table 2.

By the theory of the heuristic method, descriptors including constitutional, such as molecular weight, topological descriptor, Randic index (order 3), geometrical descriptors, moment of inertia $\mathrm{B}$ and moment of inertia $\mathrm{C}$, electrostatic descriptors, Max partial charge for a $\mathrm{H}$ atom [Zefirov's PC], Polarity parameter/square distance, etc., quantum-chemical descriptors, HOMO-1 energy, Avg bond

Table 1

The Kováts indices of 24 compounds at different temperature

\begin{tabular}{llllllll}
\hline Compounds & $0{ }^{\circ} \mathrm{C}$ & $10{ }^{\circ} \mathrm{C}$ & $20{ }^{\circ} \mathrm{C}$ & $30{ }^{\circ} \mathrm{C}$ & $40{ }^{\circ} \mathrm{C}$ & $50{ }^{\circ} \mathrm{C}$ & $60{ }^{\circ} \mathrm{C}$ \\
\hline benzene & 651.1 & 648.9 & 657.6 & 650.2 & 646.8 & 645.0 & 652.6 \\
toluene & 759.7 & 754.8 & 760.9 & 755.2 & 752.6 & 751.6 & 755.3 \\
ethylbenzene & 850.6 & 844.5 & 846.8 & 843.4 & 841.8 & 843.5 & 848.1 \\
$m$ - and $p$-xylene & 859.0 & 848.4 & 855.2 & 852.1 & 850.5 & 852.3 & 856.7 \\
$o$-xylene & 879.4 & 874.6 & 875.7 & 873.4 & 871.9 & 874.2 & 878.7 \\
methyl acetate & 520.6 & 521.0 & 526.2 & 521.3 & 515.7 & 513.8 & 511.5 \\
ethyl acetate & 609.7 & 604.4 & 611.7 & 605.1 & 600.8 & 599.3 & 597.3 \\
butyl acetate & 805.2 & 801.5 & 804.7 & 801.6 & 799.4 & 798.2 & 796.8 \\
cyclohexane & 664.1 & 660.1 & 665.7 & 662.3 & 661.2 & 661.9 & 662.9 \\
isooctane & 692.7 & 689.1 & 694.0 & 691.1 & 689.9 & 690.2 & 690.6 \\
ethanol & 376.8 & 374.5 & 374.9 & 383.5 & 378.2 & 377.1 & 378.2 \\
n-propanol & 561.2 & 561.4 & 559.3 & 558.2 & 549.7 & 543.7 & 536.9 \\
$n$-butanol & 674.4 & 674.6 & 668.2 & 665.5 & 658.4 & 653.1 & 648.2 \\
$n$-pentanol & 791.4 & 793.1 & 775.5 & 771.9 & 766.5 & 762.3 & 757.9 \\
$n$-hexanol & 889.4 & 896.8 & 870.1 & 866.3 & 862.3 & 861.1 & 859.9 \\
dichloromethane & 553.5 & 555.9 & 562.7 & 560.3 & 553.7 & 548.4 & 542.2 \\
1,1-dichloroethane & 592.2 & 593.3 & 601.6 & 598.9 & 594.2 & 590.6 & 585.9 \\
trichloromethane & 617.2 & 619.0 & 628.4 & 625.8 & 621.1 & 618.2 & 614.8 \\
1,2-dichloroethane & 645.4 & 648.2 & 656.2 & 654.0 & 650.1 & 647.7 & 644.8 \\
1-chlorobutane & 646.1 & 641.6 & 647.3 & 642.5 & 639.6 & 639 & 638.3 \\
1-bromobutane & 701.9 & 703.6 & 712.2 & 710.0 & 706.9 & 705.4 & 703.5 \\
1,1,2-triichloroethane & 742.8 & 743.1 & 748.1 & 745.1 & 741.4 & 738.7 & 735.0 \\
1-bromopentane & 809.7 & 810.2 & 813 & 810.9 & 808.5 & 807.7 & 806.5 \\
1-chlorohexane & 840.1 & 838.8 & 839.5 & 837.4 & 835.0 & 833.7 & 831.7 \\
\hline & & & & & & & \\
\hline
\end{tabular}

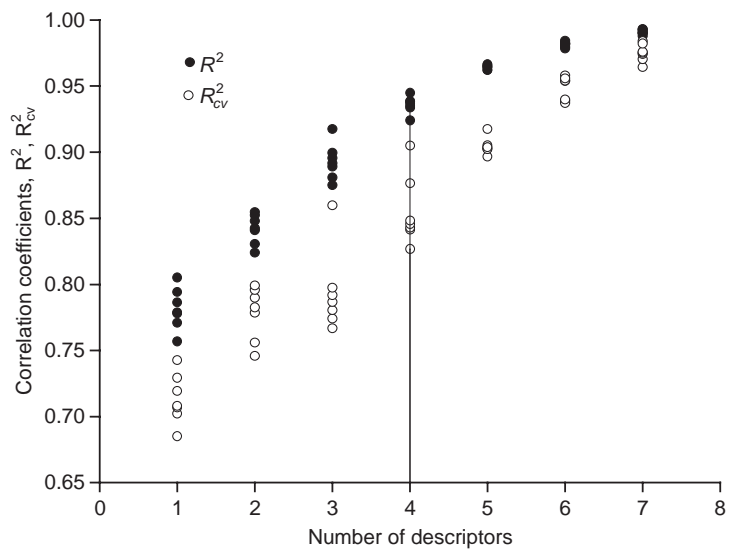

Fig. 1. Correlation coefficients $\left(R^{2}, R_{\mathrm{cv}}^{2}\right)$ versus number of descriptors.

order of a $\mathrm{C}$ atom etc., were selected in the regression equations. In the selected descriptors, quantitative structural activity relationship property, molar refractivity (MR) to retention indices was larger than other descriptors. It explained nearly $80 \%$ of the total variance for the Kováts indices (shown in Fig. 2). MR is related to the overall size of the electron cloud of a molecule and may be expressed as:

$\mathrm{MR}=4 \pi N \alpha / 3$

where $N$ is Avogadro's number and $\alpha$ is the polarizability, which is a key factor in molecule-molecule interactions and also in nonspecific molecule-solid interactions. Kiselev [18] has pointed out that heat of adsorption or interaction energy should increase with carbon number for a homologous series since polarizability increases linearly with carbon number and the gas-solid dispersion interaction is proportional to polarizability. Since MR is proportional to $\alpha$, and $\alpha$ is involved in gas-solid interactions and it can be calculated using simple molecular fragment additivity rules [19], it is used in our work conveniently. In other works [20,21], MR also is used for correlating chromatographic retention times for a series of 17 hydrocarbons and halocarbons adsorbed on Carbopack $\mathrm{C}$ carbon and for the retention indices of 373 molecules.

By using the value of Kováts indices $(I)$ (shown in Table 1), the 3-dimension chart correlated with initial temperatures, Kováts indices and the number of $\mathrm{C}$ atom of alkanol of $\mathrm{C}_{2}-\mathrm{C}_{6}$ is built (Fig. 3). It could be seen that with the increase of the number of $\mathrm{C}$ atom, the increasing tendency of the Kováts indices is basically linear. This is similar to an early observation by James and Martin [22] is the fact that the plot of the logarithms of the corrected retention volumes of the members of a homologous series versus their carbon number is a straight line when homologs of at least five or six carbon atoms are considered. Another result is that when the initial temperature is relatively low, the tendency of $I$ with the temperature the relation between the temperature and $I$ of the selected 5 homologous alcohols is nonlinear. Our explanation to this is that there is gasliquid partition process as well as gas-liquid interfacial 
Table 2

Regression equations at different initial temperatures

\begin{tabular}{|c|c|c|c|}
\hline Temperature & Descriptor & Coefficient & $t$-test \\
\hline \multirow{6}{*}{$\begin{array}{l}0{ }^{\circ} \mathrm{C} \\
R^{2}=0.9383 ; \\
\quad R_{\mathrm{cv}}^{2}=0.9048 ; \\
\quad F=72.23\end{array}$} & Intercept & 310.05 & 3.9289 \\
\hline & Moment of inertia $\mathrm{B}^{\mathrm{a}}$ & -601.31 & -3.3067 \\
\hline & Randic index (order 3$)^{\mathrm{b}}$ & 153.09 & 9.8403 \\
\hline & Max partial charge for a & 2183.30 & 5.2757 \\
\hline & $\mathrm{H}$ atom [Zefirov's $\mathrm{PC}]^{\mathrm{c}}$ & & \\
\hline & Molecular weight $^{\mathrm{d}}$ & 1.88 & 3.8117 \\
\hline \multirow{7}{*}{$\begin{array}{l}10{ }^{\circ} \mathrm{C} \\
R^{2}=0.9240 ; \\
\quad R_{\mathrm{cv}}^{2}=0.8267 ; \\
\quad F=57.73\end{array}$} & Intercept & 919.07 & 4.5332 \\
\hline & $\mathrm{MR}^{\mathrm{e}}$ & 17.50 & 10.6369 \\
\hline & DPSA-3 Difference in & 13.07 & 4.7121 \\
\hline & CPSAs (PPSA3-PNSA3) & & \\
\hline & {$[\text { Zefirov's PC] }]^{\mathrm{f}}$} & & \\
\hline & HOMO-1 energy ${ }^{\mathrm{f}}$ & 82.89 & 4.5697 \\
\hline & $\begin{array}{l}\text { Polarity parameter } \\
(\mathrm{Qmax}-\mathrm{Qmin})^{\mathrm{c}}\end{array}$ & 545.90 & 3.8660 \\
\hline \multirow{7}{*}{$\begin{array}{l}20{ }^{\circ} \mathrm{C} \\
R^{2}=0.9350 ; \\
\quad R_{\mathrm{cv}}^{2}=0.8412 ; \\
\quad F=68.34\end{array}$} & Intercept & 872.47 & 4.8548 \\
\hline & $\mathrm{MR}^{\mathrm{e}}$ & 17.247 & 11.4620 \\
\hline & DPSA-3 Difference in & 16.470 & 6.4224 \\
\hline & CPSAs (PPSA3-PNSA3) & & \\
\hline & {$[\text { Zefirov's PC }]^{\mathrm{f}}$} & & \\
\hline & HOMO-1 energy ${ }^{\mathrm{f}}$ & 75.89 & 4.7852 \\
\hline & $\begin{array}{l}\text { Polarity parameter/square } \\
\text { distance }^{\mathrm{c}}\end{array}$ & 269.88 & 3.5456 \\
\hline \multirow{7}{*}{$\begin{array}{l}30{ }^{\circ} \mathrm{C} \\
R^{2}=0.9336 ; \\
\quad R_{\mathrm{cv}}^{2}=0.8427 ; \\
\quad F=66.75\end{array}$} & Intercept & 841.76 & 4.6830 \\
\hline & $\mathrm{MR}^{\mathrm{e}}$ & 17.09 & 11.3839 \\
\hline & DPSA-3 Difference in & 12.41 & 4.8813 \\
\hline & CPSAs (PPSA3-PNSA3) & & \\
\hline & {$[\text { Zefirov's PC }]^{\mathrm{f}}$} & & \\
\hline & HOMO-1 energy ${ }^{\mathrm{f}}$ & 72.66 & 4.5947 \\
\hline & $\begin{array}{l}\text { Max partial charge for a } \\
\mathrm{H} \text { atom [zefirov's } \mathrm{PC}]^{\mathrm{c}}\end{array}$ & 1448.70 & 3.4981 \\
\hline \multirow{7}{*}{$\begin{array}{l}40^{\circ} \mathrm{C} \\
R^{2}=0.9370 ; \\
\quad R_{\mathrm{cv}}^{2}=0.8455 ; \\
\quad F=70.62\end{array}$} & Intercept & 838.82 & 4.7363 \\
\hline & $\mathrm{MR}^{\mathrm{e}}$ & 17.40 & 11.7333 \\
\hline & DPSA-3 Difference in & 16.15 & 6.3902 \\
\hline & CPSAs (PPSA3-PNSA3) & & \\
\hline & {$[\text { Zefirov's PC }]^{\mathrm{f}}$} & & \\
\hline & HOMO-1 energy ${ }^{\mathrm{f}}$ & 73.46 & 4.7002 \\
\hline & $\begin{array}{l}\text { Polarity parameter/square } \\
\text { distance }^{\mathrm{f}}\end{array}$ & 265.83 & 3.5437 \\
\hline \multirow{7}{*}{$\begin{array}{l}50{ }^{\circ} \mathrm{C} \\
R^{2}=0.9384 ; \\
\quad R_{\mathrm{cv}}^{2}=0.8481 ; \\
\quad F=72.40\end{array}$} & Intercept & 835.21 & 4.7302 \\
\hline & $\mathrm{MR}^{\mathrm{e}}$ & 17.51 & 11.8466 \\
\hline & DPSA-3 Difference in & 15.95 & 6.3311 \\
\hline & CPSAs (PPSA3-PNSA3) & & \\
\hline & {$[\text { Zefirov's PC }]^{\mathrm{f}}$} & & \\
\hline & HOMO-1 energy ${ }^{f}$ & 73.32 & 4.7053 \\
\hline & $\begin{array}{l}\text { Polarity parameter/square } \\
\text { distance }^{\mathrm{c}}\end{array}$ & 260.02 & 3.4791 \\
\hline \multirow{5}{*}{$\begin{array}{l}60{ }^{\circ} \mathrm{C} \\
R^{2}=0.9448 ; \\
\quad R_{\mathrm{cv}}^{2}=0.8764 ; \\
\quad F=81.37\end{array}$} & Intercept & 2918.70 & 8.0136 \\
\hline & $\begin{array}{l}\text { Gravitation index } \\
\text { (all bonds) })^{\mathrm{d}}\end{array}$ & 0.84 & 9.2811 \\
\hline & Avg bond order of a C atom ${ }^{f}$ & -2730.60 & -6.8819 \\
\hline & Min partial charge $(\mathrm{Qmin})^{\mathrm{c}}$ & -621.50 & -4.0680 \\
\hline & Moment of inertia $C^{a}$ & -595.85 & -3.0720 \\
\hline
\end{tabular}

${ }^{a}$ Geometrical descriptor.

b Topological descriptor.

c Electrostatic descriptor.

d Constitutional descriptor.

e Quantitative structural activity relationship properties descriptor.

f Quantum-chemical descriptor.

adsorption in the process of gas chromatographic retention (shown in Eq. (1)). At the relatively high initial temperature, gas-liquid partition process is effective to the retention behavior. While, with the decrease of the initial temperature, the contribution of gas-liquid interfacial adsorption process is becoming more and more important. And perhaps this brings out the nonlinear relationship of the temperature and $I$.

\subsection{Capacity factor}

In chromatographic work, capacity factor $\left(k^{\prime}\right)$ is a simple but very useful parameter. Many works have shown that with the increase of column temperature, the GC retention time of solutes is always decreasing. If we suppose that enthalpy of solutes are approximately invariability at different temperature, the logarithm of $k^{\prime}$ can be expressed as [23]:

$\ln k^{\prime}=A+B / T$

where $A$ and $B$ are constant, $T$ is Kelvin temperature.

In this paper, at the range of $0-60{ }^{\circ} \mathrm{C}$, we studied the change of $k^{\prime}$ of selected compounds with the different initial temperature and capacity factors versus carbon numbers of the different series of compounds were shown in Fig. 4 . The results indicated that at relative low initial temperature, the linear relation between $\ln k^{\prime}$ and $1 / \mathrm{T}$ still exists of $n$-alkane, benzene series, acetate, alkanol and alkyl halide. Perhaps at this temperature range, the change of the heat of solution of the solutes is little, so the influence of temperature to the linear relation can also be ignored.

\subsection{Relationship between carbon number and retention behavior}

Previous works have showed that there is approximate linear relationship between the logarithm of retention time and in the certain range carbon number:

$\ln t^{\prime}=A_{1} n+C_{1}$

where $n$ is the carbon number, $A_{1}$ and $C_{1}$ is the constant, respectively. The rule is in adaptation to aliphatic com-

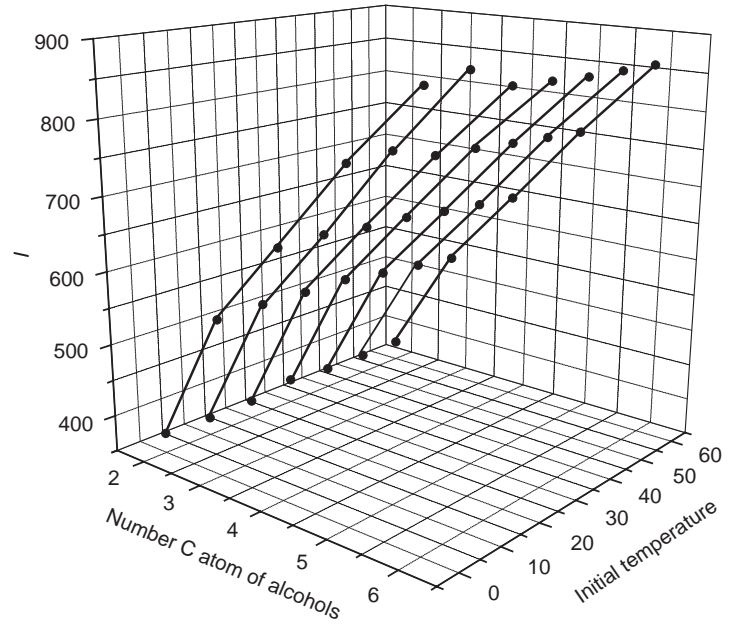

Fig. 2. The relationship between molar refractivity (MR) and the Kováts indices. 

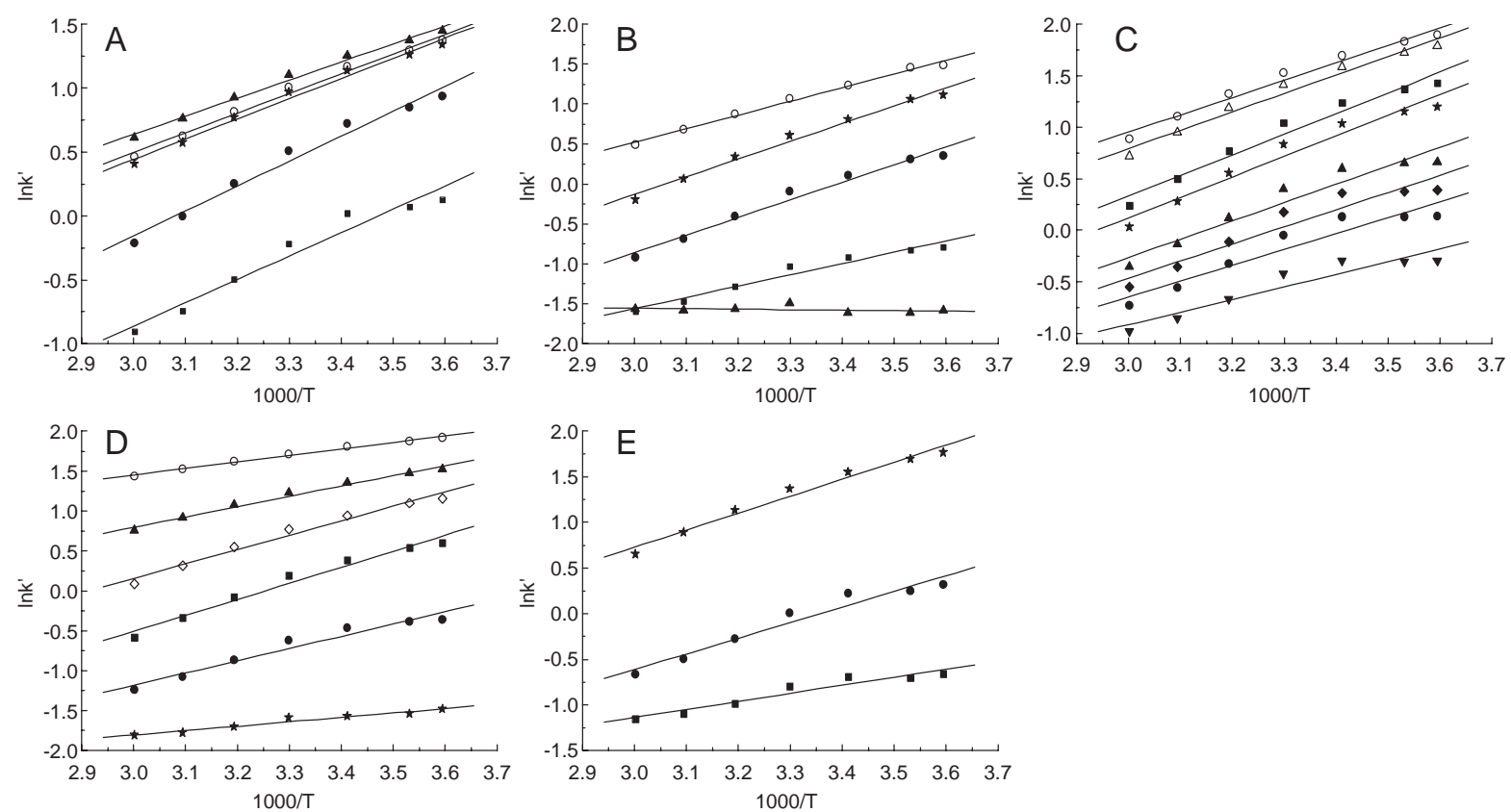

Fig. 3. Correlation of $I$ (alcohols selected), number $\mathrm{C}$ atom of alcohols and initial temperatures.

pound, $n$-alkane, alcohols and methyl ketone, etc. Thereinto, the factors that affect coefficients are molecular polarizability and molar volume. For the compounds, which the carbon numbers are relatively small, the molecular ploarizability and molar volume of homology have the property of additivity. With the increase of the carbon
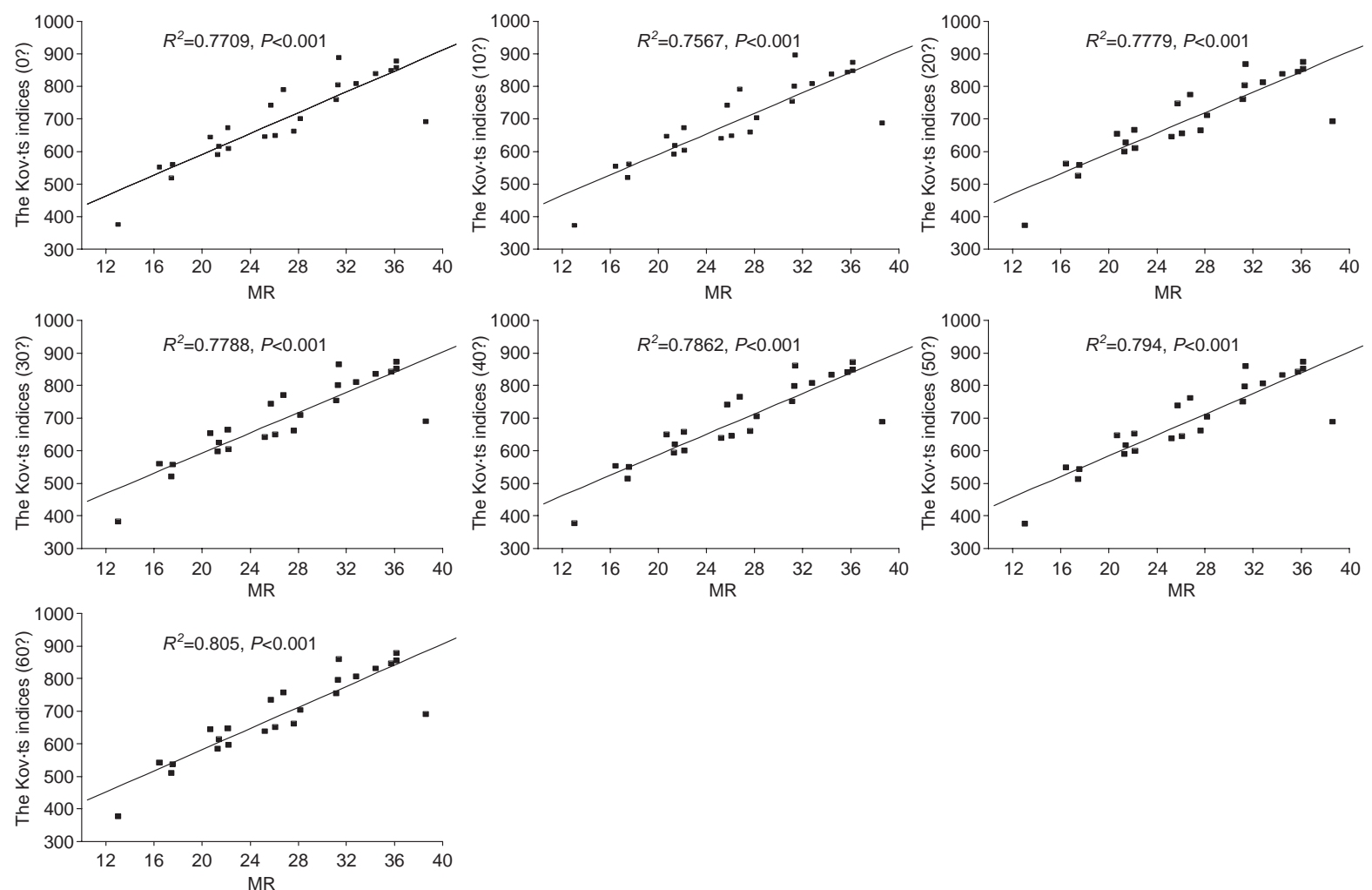

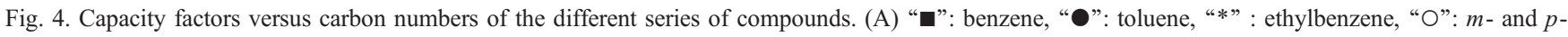

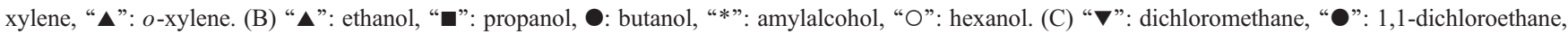

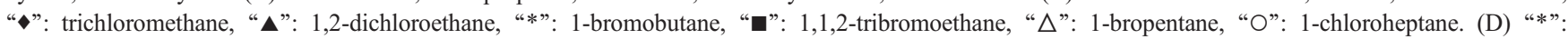

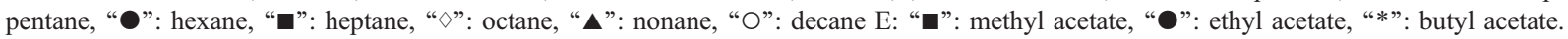


number, the departure of additivity comes into being, and then the departure of the upper linear relation comes into being.

Fig. 5 showed the relationship between the carbon number and the logarithm of retention time of $n$-alkane, alkanol and acetate at the initial temperature $0{ }^{\circ} \mathrm{C}, 20{ }^{\circ} \mathrm{C}$, $40{ }^{\circ} \mathrm{C}$ and $60{ }^{\circ} \mathrm{C}$. It was shown that at the relative low initial temperature $0{ }^{\circ} \mathrm{C}, 20{ }^{\circ} \mathrm{C}$, the deviation from the fitted line of the compounds which have more carbon were large. But with the increment of initial temperature $\left(40{ }^{\circ} \mathrm{C}\right.$ and $60{ }^{\circ} \mathrm{C}$ ), the deviation were becoming lower and lower. Chen et al. [24] pointed out that when the carbon number is increasing, the increment of interfacial adsorption is larger than that of partition. That is to say, it is interfacial adsorption that leads the deviation from the linear correlation. While the increase of initial temperature can decrease the distribution of interfacial adsorption for lowpolar compounds (for example, $n$-alkane), so the trend reflected was obtain in Fig. 4.

\subsection{Resolution}

Usually, resolution, $R_{\mathrm{S}}$ is used to evaluate separated performance, which is defined as:

$R_{2}=2\left(\frac{t_{\mathrm{R} 2}-t_{\mathrm{R} 1}}{W_{\mathrm{k} 1}-W_{\mathrm{k} 2}}\right)$

where $t_{\mathrm{R} 1}$ and $t_{\mathrm{R} 2}$ is retention time compound 1 and compound 2, respectively, $W_{\mathrm{k} 1}$ and $W_{\mathrm{k} 2}$ is the breadth of peak base of compound 1 and compound 2, respectively.

$R_{\mathrm{s}}$ is influenced by dynamics of chromatographic system, operating condition (for example, flow rate of carrier gas), and the thermodynamic properties of solutes (for example, adsorption constant and partition constant). We studied the influence of initial temperature to $R_{\mathrm{S}}$. The results showed $R_{\mathrm{s}}$ was significantly increased with the decrease of initial temperature. But when the temperature was lower than 30 ${ }^{\circ} \mathrm{C}$, the content of increase was slow down.

\section{Conclusions}

The Kováts indices $(I)$ of 24 volatile organic compounds were measured at the differelnt initial temperatures by a cryogenic chromatographic apparatus. After calculating their quantitative-chemical parameters, the seven quantitative correlation models at different initial temperatures between the Kováts indices and the parameters of 24 volatile organic compounds by using the heuristic method of CODESSA were obtained. Comparing with previous study on gas chromatography, it can be seen that:

(i) The increasing tendency of the Kováts indices in cryogenic chromatographic system is basically linear with the increase of the number of $\mathrm{C}$ atom. But the tendency of $I$ with the temperature is nonlinear, which proves that the contribution of gas-liquid interfacial adsorption process is more important than normal chromatographic system. In the range of $0-60{ }^{\circ} \mathrm{C}$ of initial temperature, $\mathrm{MR}$ is a important descriptor to influence the retention behavior of selected compounds.

(ii) The linear relation between $\ln k^{\prime}$ and $1 / T$ still exists of $n$-alkane, benzene series, acetate, alkanol and alkyl halide at relative low initial temperature.

(iii) The deviation from the fitted line of the compounds which have more carbon were large at initial temperature $0-20{ }^{\circ} \mathrm{C}$. But with the increment of initial temperature $\left(40-60{ }^{\circ} \mathrm{C}\right)$, the deviation are becoming lower and lower.
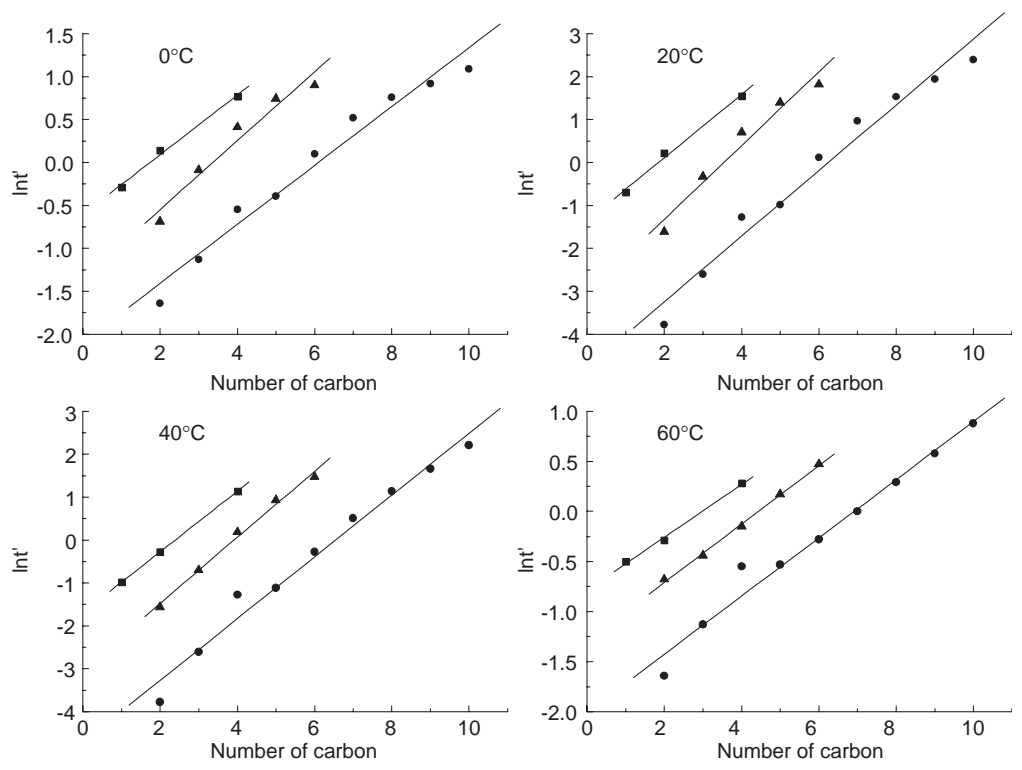

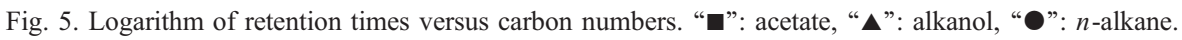


(iv) $R_{\mathrm{s}}$ is significantly increased with the decrease of initial temperature. But when the temperature was lower than $30{ }^{\circ} \mathrm{C}$, the content of increase begin to slow down.

\section{Acknowledgments}

This work is supported by the National Basic Research Program of China (2003CB415001) and Natural Science Foundation of China (20407003).

\section{References}

[1] J.A. Yancey, J. Chromatogr. Sci. 32 (1994) 349.

[2] V.S. Ong, R.S. Hites, Anal. Chem. 63 (1991) 2829.

[3] B.R. Kersten, C.F. Poole, J. Chromatogr. 399 (1987) 1.

[4] C.F. Poole, S.K. Poole, Chem. Rev. 89 (1989) 377.

[5] D.F. Fritz, A. Sahil, E. Kovats, J. Chromatogr. 186 (1979) 63.

[6] C.T. Peng, S.F. Ding, R.L. Hua, Z.C. Yang, J. Chromatogr. 436 (1988) 137.

[7] R.L. Martin, Anal. Chem. 33 (1961) 347.

[8] E.Sz. Kovats, Helv. Chim. Acta 41 (1958) 1915.

[9] E. Kovats, Adv. Chromatogr. 1 (1965) 229.
[10] G. Tarjan, Sz. Nyiredy, M. Gyor, E.R. Lombosi, T.S. Lombosi, M.V. Budahegyi, S.Y. Meszaros, J.M. Takacs, J. Chromatogr. 472 (1989) 1 .

[11] M.V. Budahegyi, E.R. Lombosi, T.S. Lombosi, S.Y. Meszaros, Sz. Nyiredy, G. Tarjan, I. Timar, J.M. Takacs, J. Chromatogr. 271 (1983) 213.

[12] H. Rotzsche, vol. 48, Elsevier, Amsterdam, 1991.

[13] J.M. Liu, G.B. Jiang, J.F. Liu, Q.F. Zhou, Z.W. Yao, J. Sep. Sci. 26 (2003) 629 .

[14] J.M. Liu, Q.F. Zhou, G.B. Jiang, J.F. Liu, J.Y. Liu, M.J. Wen, J. AOAC Int. 86 (2003) 461.

[15] A.R. Katritzky, V.S. Lobanov, M. Karelson, Reference Manual, Version 2.13; 1995-1997.

[16] A.R. Katritzky, V. Lobanov, M. Karelson, Chem. Soc. Rev. 24 (1995) 279.

[17] MOPAC, v.6.0 Quantum Chemistry Program Exchange, Program 455; Indiana University: Bloomington, IN, 1989.

[18] A.V. Kiselev, Proc. 1st Int. Conference on Zeolites," London, 1967, p. 252.

[19] C. Hansch, A. Leo, Am. Chem. Soc., Washington, DC, 1995.

[20] T.R. Rybolt, D.L. Logan, M.W. Milburn, H.E. Thomas, A.B. Waters, J. Colloid Interface Sci. 220 (1999) 148.

[21] R.R. Thomas, N.H. Dana, B.S. Jessica, E.T. Howard, L.B. Mitcell, J. Colloid Interface Sci. 234 (2001) 168.

[22] A.T. James, A.J.P. Martin, Biochem. J. 50 (1952) 679.

[23] P.Z. Lu, C.Z. Dai, Theoretical Basis of Chromatography, Science Press, Beijing, 1989, p. 187.

[24] J.P. Chen, L.F. Zhang, Y.Z. Tian, Chin. J. Chromatogr. 16 (1998) 6. 